\title{
O diálogo entre biblioteca e comunidade: um estudo de caso acerca do perfil e das percepções dos usuários das Bibliotecas Comunitárias de Itaitinga, Ceará
}

Ana Pricila Celedonio da Silva

Mestranda em Ciência da Informação pela Universidade Federal do Ceará (UFC). Bacharel em Biblioteconomia pela Universidade Federal do Ceará (UFC)

Lidia Eugenia Cavalcante

Doutora em Educação pela Universidade Federal do Ceará. Professora do Programa de PósGraduação em Ciência da Informação da UFC (PPGCI/UFC)

Maria de Fátima Oliveira Costa

Doutora em Ciência da Informação pelo programa de Pós-Graduação em Ciência da Informação da Universidade Estadual Paulista (UNESP). Professora do Programa de Pós-Graduação em Ciência da Informação da UFC (PPGCI/UFC)

http://dx.doi.org/10.1590/1981-5344/3138

Apresenta estudo de caso acerca das bibliotecas comunitárias do município de Itaitinga-CE. Aborda questões referentes aos estudos de usuários da informação e da realização dos mesmos em contextos locais. Tem como objetivos: identificar o perfil dos usuários das bibliotecas comunitárias de Itaitinga-CE e averiguar qual a percepção dos mesmos acerca das bibliotecas de sua comunidade. $O$ delineamento metodológico da pesquisa se deu pelos pressupostos do 
estudo de caso, em que foram analisados três casos de bibliotecas comunitárias localizadas em zonas rurais do referido município. A pesquisa possui natureza mista, visto que contempla aspectos quantitativos e qualitativos no processo de análise dos dados coletados por meio de questionário. Correlacionados aos nossos objetivos, os resultados apontam que os usuários das bibliotecas comunitárias analisadas são, na maioria, crianças e jovens, sendo observada ainda, relevante participação de usuários de outras faixas etárias. De modo geral, os participantes do estudo revelam integrar-se principalmente às ações voltadas à leitura e atividades culturais promovidas pelas bibliotecas. A percepção dos usuários acerca desses espaços revela o entendimento de que as bibliotecas são importantes para as comunidades, principalmente pela possibilidade de acesso ao livro, a leitura e a realização de atividades de cunho cultural.

Palavras-chave: Bibliotecas Comunitárias. Estudos de Usuários da Informação. Usuários em Contextos Locais. Biblioteca e Comunidade.

\section{The dialogue between library and community: a case study about the profile and perceptions of the users of the Community Libraries of Itaitinga, Ceará}

It presents a case study about the community libraries of the municipality of Itaitinga-CE. It addresses issues related to the studies of information users and their realization in local contexts. Its objectives are: to identify the profile of the users of these community libraries in Itaitinga-CE, and to investigate their perceptions about the libraries of their communities. The methodological design of the research was based on the assumptions of the case study, which analyzed three cases of community libraries located in rural areas of said municipality. The research has a mixed nature, since it includes quantitative and qualitative aspects in the data analysis, which were collected through a questionnaire. The results of the research indicate that the users of the community libraries analyzed are mostly children and young people, and a relevant participation of users of other age groups 
is also observed. Participants in the study reveal that they are mainly engaged in reading and cultural activities promoted by libraries. The perception of users about these spaces reveals the understanding that libraries are important for the community, especially for the possibility of access to books and reading, and cultural activities.

Keywords: Community Library. Studies of Information Users. Users in Local Contexts. Library and Community.

Recebido em 26.04.2017 Aceito em 23.10.2017

\section{Introdução}

A informação tem sido elemento intrínseco às discussões que envolvem o cenário contemporâneo. Fazem parte dessas deliberações temas como: igualdade social, cidadania, inclusão social, dentre outros. No bojo dessas discussões, emergem, (principalmente no âmbito da Biblioteconomia e da Ciência da Informação) questões sobre o papel social das unidades de informação, como por exemplo, as bibliotecas públicas e as bibliotecas comunitárias e o papel que desempenham no processo de democratização da informação.

Em meio a esse cenário, testemunha-se, nas últimas décadas, forte movimento de criação e implantação de bibliotecas comunitárias nas diferentes regiões brasileiras. Essas bibliotecas, de modo geral, apresentam-se como projetos sociais oriundos de iniciativas comunitárias que visam especialmente a democratização do acesso à leitura e à informação.

Esses espaços diferem de outros tipos de bibliotecas, visto que possuem uma gestão realizada de forma participativa, autônoma e horizontal. Nessa gestão, o diálogo entre biblioteca e comunidade torna-se essencial para o sucesso e o alcance da missão e dos objetivos dessas iniciativas. Conhecer a comunidade e os usuários do local onde se insere, constitui-se $o$ primeiro passo a ser realizado na implantação e manutenção de uma biblioteca comunitária.

Esse diálogo poderá se dar de diversas formas, dentre elas, nos estudos de comunidade e usuários da informação que, para além do âmbito das bibliotecas comunitárias, são essenciais para o funcionamento adequado de qualquer unidade de informação. Esses estudos estão inseridos no campo da Ciência da Informação (CI) e podem ser compreendidos como: investigações cujo foco encontra-se em descobrir os perfis, as demandas e os usos da informação por parte de seus usuários. De acordo com Araújo (2012), esses estudos possuem três principais abordagens, a saber: a Abordagem Tradicional, Abordagem Alternativa e a Abordagem Interacionista. E segundo o autor, essas abordagens estariam entrelaçadas aos paradigmas Físico, Cognitivo e Social do pensamento de Capurro (2003). 
Constituem-se como tendência na CI e nos estudos de usuários, as pesquisas ligadas ao caráter social da informação (ARAÚJO, 2012). Nessa perspectiva, estariam inseridos os trabalhos acerca das bibliotecas comunitárias e os estudos de usuários em contextos locais. Acompanhando esse cenário, o estudo ora apresentado, configura-se como um estudo de caso acerca das bibliotecas comunitárias de ItaitingaCeará, que teve como objetivos: identificar o perfil dos usuários dessas bibliotecas e averiguar a percepção dos mesmos acerca das bibliotecas comunitárias de suas comunidades.

Os enfoques temáticos apresentados neste estudo envolvem, inicialmente, os conceitos e as abordagens dos estudos de usuários da informação e as relações entre a biblioteca comunitária e os estudos de usuários em contextos locais. Apresenta, ainda, os aspectos metodológicos que guiaram o estudo e os resultados da pesquisa, onde se discute sobre o perfil e as percepções dos usuários das bibliotecas comunitárias analisadas.

\section{Conceitos e abordagens dos estudos de usuários da informação}

Os estudos de usuários da informação fazem parte do grande leque de disciplinas que estão inseridas na Ciência da Informação. Passando por diferentes abordagens, esses estudos vêm cada vez mais se destacando na área através de um novo olhar dado à informação e a seus usuários.

Considerando os aspectos conceituais aplicados a estes estudos, recorremos inicialmente à perspectiva de Figueiredo (1994, p. 7), que afirma que estes se constituem em investigações realizadas com o intuito de descobrir o que "os indivíduos precisam em matéria de informação, ou então para saber se as necessidades de informação por parte dos usuários [...] estão sendo satisfeitas de maneira adequada".

Em uma perspectiva semelhante, mas que amplia a definição desses estudos, Costa (2016, p. 68) reflete acerca da conceituação dos estudos de usuários da informação e os define como,

[...] o conjunto de conhecimentos, ou disciplina, pertencente à área da Ciência da Informação para compreender, por meio de investigações, e detectar o que o usuário necessita em matéria de informação, buscando interação entre usuário e informação, ampliando e interferindo na sua produção.

Dias e Pires (2004, p. 10) contemplam também os usuários potenciais de informação, ao afirmarem que "os estudos de usuários são uma investigação que objetiva identificar e caracterizar os interesses, as necessidades e os hábitos de uso de informação de usuários reais e/ou potenciais de um sistema de informação."

Dessa maneira, compreende-se que os estudos de usuários são investigações cujo foco encontra-se no usuário da informação, em suas necessidades e demandas informacionais e, ainda, na forma com o 
mesmo se comporta para solucionar essas demandas, e no uso que fazem da informação.

Como foi dito anteriormente, Araújo (2012) nos apresenta três principais enfoques nos estudos de usuários, que de acordo com o autor, se relacionam aos paradigmas Físico, Cognitivo e Social, propostos por Capurro (2003).

Ao traçar as relações existentes entre os paradigmas de Capurro (2003) e os estudos de usuários, Araújo (2012) reflete incialmente acerca da Abordagem Tradicional, na qual se concentram os primeiros estudos de usuários, de caráter pragmático, positivista, usados como instrumentos de diagnósticos para as bibliotecas, como indicadores, baseando-se em um modelo funcionalista. À esta abordagem estaria relacionado o Paradigma Físico, no qual entende-se a informação "como um fenômeno objetivo, com existência independente dos sujeitos e dos contextos, algo possível de ser transmitido tal como é de um ponto a outro num processo de comunicação." (ARAÚJO, 2012, p. 146).

O Paradigma Físico corresponde à primeira abordagem dada à informação no campo da CI, surgido da Teoria Matemática da Comunicação de Claude Shannon e Warren Weaver (1949). Dessa forma, é possível perceber que, na Abordagem Tradicional dos estudos de usuários, esses primeiros estudos convergem com as primeiras perspectivas aplicadas aos estudos acerca da informação no âmbito da CI. No sentido objetivo e pragmático dado à informação, encontram-se semelhanças na forma como os primeiros estudos de usuários acontecem.

$\mathrm{Na}$ segunda abordagem, a Alternativa, os interesses desses estudos passam a ter seu foco mais propriamente nos usuários, esses como seres cognoscentes. Conforme já sinalizado por Araújo (2012), esse enfoque está relacionado com o segundo paradigma da CI, o Paradigma Cognitivo. Neste momento,

[...] a informação passa a ser entendida como algo capaz de alterar os estados cognitivos dos sujeitos, dando-se, a partir daí é dada especial atenção às maneiras como os indivíduos percebem seus estados de lacuna cognitiva e as estratégias utilizadas por eles para buscar e usar as informações de que necessitam. (ARAÚJO, 2012, p. 148).

Um marco dessa segunda abordagem, diz respeito ao modelo Sense Making de Dervin (1986), sobre ele, Araújo (2012) aponta que o objetivo da autora foi o de "ampliar os modelos propostos para que se pudessem incorporar novas dimensões do problema, como a multi-direcionalidade do processo e as múltiplas estratégias levadas a termo pelos usuários." (ARAÚJO, 2012, p. 148). Na perspectiva de Dervin (1986), o processo de busca e uso da informação não seria mais entendido como uma sequência de ações encadeadas e o usuário visto como ser ativo construtor dos diferentes significados e possibilidades.

Quanto a Abordagem Interacionista, Araújo (2012) indica que essa estaria relacionada ao Paradigma Social. Nesse último paradigma, leva-se em consideração a natureza social e coletiva da informação, seu 
enraizamento em um determinado contexto e ainda o caráter ativo do usuário e, nesse momento, a interação é posta como um conceito chave para os novos estudos de usuários.

Esse enfoque surge em um contexto de eclosão de movimento sociais nos países da América Latina, juntamente com discussões que envolvem temas como o acesso à informação, inclusão informacional, cidadania e sociedade da informação. (ARAúJO, 2012)

Percebe-se que na Abordagem Interacionista, os estudos de usuários da informação buscam compreender esse usuário não somente por meio de suas atitudes e comportamentos de busca e uso da informação, mas também a partir do contexto em que o mesmo está inserido. Nesses estudos, a análise comtempla o conjunto: usuário e comunidade, o indivíduo e o local no qual vive e experimenta os diversos caminhos pelos quais a informação perpassa. A ideia, nessa última abordagem, seria a de que, se analisarmos os contextos e as dinâmicas sociais em que os usuários estudados estão envolvidos, poderemos compreender de forma mais adequada como o complexo movimento informacional acontece.

Desse modo, observa-se que os estudos de usuários têm acompanhado as tendências e as perspectivas de estudo no campo da CI. A abordagem interacionista desses estudos, acompanhada do Paradigma Social, abre caminho para diversas perspectivas, a exemplo dos estudos de usuários em contextos locais e as bibliotecas comunitárias.

\section{Reflexões acerca da Biblioteca Comunitária e dos estudos de usuários em contextos locais}

Marcadas por uma forte função social, as bibliotecas comunitárias vêm assumindo uma luta pela promoção do acesso à leitura e à informação. No cenário brasileiro, essas bibliotecas podem ser configuradas como projetos sociais autônomos sem vínculo direto com instituições governamentais, que podem possuir ou não articulações com instâncias públicas e privadas locais, sendo lideradas por grupos organizados de pessoas, que possuem "o objetivo comum de ampliar o acesso da comunidade à informação, à leitura e ao livro, com vistas a sua emancipação social." (MACHADO, 2008, p. 64)

Algumas caraterísticas desse tipo de biblioteca são: a sua forma de constituição, visto que são formadas e criadas pela comunidade a que pertencem; o combate conjunto à exclusão informacional como forma de possibilitar a igualdade e justiça social; o processo de articulação dos indivíduos da comunidade; a localização dentro de uma comunidade; e o fato de não estarem ligadas diretamente a órgãos governamentais. (MACHADO, 2008).

Nessa perspectiva, percebe-se que a gestão autônoma e participativa, a inserção em uma comunidade, a promoção da leitura e a inclusão informacional são aspectos intrínsecos à concepção de biblioteca comunitária. A gestão participativa acontece por meio da intervenção e 
participação dos indivíduos nas ações e no planejamento da biblioteca (MACHADO, 2008). A inserção em uma comunidade pode ser entendida para além de uma referência territorial, mas também pelos significados que a palavra comunidade evoca, como o sentimento de pertencimento, de lutas em comum, de laços afetivos e familiares (BAUMAN, 2003). A promoção da leitura e a inclusão informacional podem ser compreendidas como os principais objetivos dessas bibliotecas. Entretanto, para o alcance desses objetivos, é necessário que a atuação da biblioteca esteja voltada para as demandas informacionais e sociais da comunidade em que se insere (MACHADO, 2008).

Através desses aspectos, é possível perceber a existência de uma forte função e potencial de atuação social e cultural ligados à biblioteca comunitária. Freire (1984) defende esse papel quando afirma que,

A biblioteca popular, como centro cultural e não como um depósito silencioso de livros, é vista como um fator fundamental para o aperfeiçoamento e a intensificação de uma forma correta de ler o texto em relação ao contexto. Daí a necessidade de uma biblioteca popular centrada nesta linha de estimular a criação de horas de trabalho em grupos, em que se façam verdadeiros seminários de leitura, ora buscando o adentramento crítico no texto, procurando aprender a sua significação mais profunda, ora propondo aos leitores uma experiência estética, de que a linguagem popular é intensamente rica. (FREIRE, 1984, p. 38).

Os serviços oferecidos nesses espaços podem ser bastante diversos, refletindo nas demandas da comunidade e no nível de interação e participação da mesma com a biblioteca. Esses serviços podem estar ligados às ações de fomento à leitura, a educação, atividades culturais e diferentes tipos de movimentos. Machado (2008) identifica algumas atividades realizadas no âmbito dessas bibliotecas, sendo elas: a mediação de leitura, saraus literários, cursos de capacitação e aperfeiçoamento, palestras, seminários, concursos de poesia, oficinas, além daqueles serviços tradicionais, tais como, empréstimo e pesquisa local.

Quanto aos usuários das bibliotecas comunitárias, Machado (2008) indica que, de modo geral, esses poderão ser formados por diversos grupos, como crianças, jovens, adultos e idosos. Essa diversidade de grupos de usuários se justifica pelo fato de que as bibliotecas comunitárias se mobilizam em um esforço conjunto para 0 atendimento das necessidades educacionais e culturais de toda a comunidade. Todavia, a autora afirma que, em alguns casos, essas bibliotecas podem direcionar seus esforços para grupos específicos da comunidade, devido a alguma necessidade específica que ali se apresenta.

Tendo em vista essas considerações, torna-se então necessário compreender que a comunidade como um todo possui status de usuário potencial da biblioteca comunitária e que os indivíduos que compõem essas comunidades, ao mesmo tempo em que formam diversos grupos, possuem também diferentes necessidades e demandas informacionais. 
Para conhecer essas demandas, estudos de comunidade e de usuários tornam-se, então, imprescindíveis.

Para realização desses estudos é importante ter em mente que as necessidades e fluxos informacionais presentes em contextos locais assumem naturezas bastante diversas. O que indica que essa sondagem precisa acontecer de forma dialógica, pois os usuários da informação em contextos locais desejam, muitas vezes, não somente dados informacionais, mas, processos comunicacionais de informação. É importante ter em mente que "pensar as demandas informacionais das comunidades locais é aferir a elas novas formas de mediação." (CAVALCANTE, 2014, p. 261).

Os usuários em contextos locais são, como destaca Cavalcante (2014, p. 262), "tão híbridos em suas demandas quanto às informações que desejam receber $e$ as muitas que podem produzir sobre seus contextos, memórias e identidades comunitárias." Diante desse princípio, observamos que, diferentemente de outros tipos de bibliotecas, as necessidades e demandas presentes no âmbito das bibliotecas comunitárias serão tão diversas quanto os grupos das comunidades em que se inserem, então, por consequência, os serviços e ações ofertados deverão ser pensados com foco nas demandas dessas comunidades.

Com particularidades assim tão diversas, como a gestão da biblioteca comunitária poderia buscar conhecer as características de sua comunidade de usuários? Rémy (2014) indica alguns questionamentos iniciais que podem nortear essa busca, sendo eles: qual a história da comunidade? Do que a comunidade vive? Quais as principais fontes de renda? Quais os interesses da comunidade? Que grupos compõe a comunidade? Qual o grau de escolaridades desses grupos? Como e quais os problemas identificados no contexto da comunidade?

Destarte, entendemos que os estudos da comunidade e dos usuários podem vir a auxiliar a biblioteca comunitária no desempenho de sua missão e dos objetivos na comunidade em que se insere. Combinando estudos que levem em consideração os aspectos supracitados e as dinâmicas e fluxos informacionais, a biblioteca estará cada vez mais próxima do cumprimento de sua missão e do alcance de suas finalidades.

\section{Aspectos metodológicos do estudo}

O estudo das percepções e do perfil dos usuários das bibliotecas comunitárias do município de Itaitinga, localizado no Estado do Ceará (CE), foi delineado com base nos pressupostos metodológicos de estudo de caso, o qual se configura como um estudo de um ou mais objetos, inseridos em um determinado contexto, que pretende descrever a situação estudada e explicar as variáveis causais dos fenômenos (GIL, 1999).

A pesquisa foi formada pela análise de três estudos de caso, sendo cada um deles referente a uma das bibliotecas comunitárias pertencentes ao município de Itaitinga-CE. Localizadas em zonas rurais do referido 
município, as bibliotecas analisadas possuem em comum, dentre outros aspectos, o fato de terem sido criadas como parte integrante do Projeto Ler Para Crer: oficinas itinerantes para a implantação de bibliotecas comunitárias em municípios cearenses, projeto de extensão do Departamento de Ciências da Informação da Universidade Federal do Ceará (UFC).

Os objetos constituintes de cada estudo de caso, (que são as bibliotecas comunitárias de Itaitinga-CE) são descritas brevemente a seguir:

Caso 1 - Biblioteca Comunitária Denise Ferreira Luz (BCDFL), localizada na comunidade denominada Alto do Bode, Gereraú. Foi implantada no ano de 2009, e possui cerca de noventa usuários cadastrados. Os principais serviços oferecidos à comunidade são: atendimento e empréstimo de livros, atividades de leitura e contação de histórias, apresentações teatrais, aulas de violão, oficinas de arte, artesanato e reciclagem, reforço escolar e alfabetização, patinação, aulas de aeróbica e atendimento médico gratuito quinzenal.

Caso 2 - Biblioteca Comunitária Laura Barros (BCLB), implantada na comunidade de Carapió no ano de 2009, possui cerca de 300 usuários cadastrados, sendo estes usuários também de comunidades próximas e do centro de Itaitinga. Dentre os principais serviços oferecidos, destacamse atividades tais como: empréstimo de livros, rodas de leitura e contação de histórias, atividades de pintura e desenho, atividades religiosas e outras atividades de cunho cultural e de lazer.

Caso 3 - Biblioteca Comunitária Margarida Machado (BCMM), localizada na comunidade de Vila Machado, teve sua implantação também no mesmo ano. Seus principais serviços se constituem em: empréstimo de livros, rodas de leitura e contação de histórias, aulas de capoeira, aulas de teatro, apresentações teatrais e oficinas de artesanato. E atende a aproximadamente cerca de 150 usuários cadastrados.

A coleta de dados para identificação do perfil dos usuários e de suas percepções quanto à biblioteca, se deu mediante aplicação de questionários de natureza mista, contendo questões fechadas e abertas. Participaram da pesquisa um quantitativo de cinquenta usuários das bibliotecas comunitárias estudadas.

Configurada em uma análise quati-qualitativa, a apreciação dos dados coletados foi realizada de forma a contemplar tanto os aspectos quantitativos, quanto qualitativos dos dados, dando especial atenção a estes últimos. Dessa maneira, os dados colhidos por meio dos questionários serviram como base para uma análise, cujo foco esteve em compreender como as variáveis apresentadas interagem com os aspectos e as percepções reveladas pelos participantes da pesquisa.

Nesse intuito, foram estabelecidos alguns pontos para orientar este estudo. Considerou-se, inicialmente, os dados demográficos, como idade e escolaridade. Seguindo-se de aspectos, tais como: a frequência de utilização pelos usuários da biblioteca, além das atividades e serviços por ele utilizados. No que se refere a opinião dos usuários, buscou-se 
descobrir os sentidos atribuídos por eles à biblioteca comunitária, como, a importância da biblioteca, as melhorias trazidas pela mesma à comunidade e, também, os aspectos em que esta poderia vir a melhorar.

Para subsidiar a análise desses aspectos, foram utilizados os critérios para classificação de tipos de usuários da informação de Amaral (2014 ${ }^{1}$ apud CUNHA; AMARAL; DANTAS, 2015). Os critérios apontados pela autora e utilizados na análise do estudo foram: o uso que é feito da unidade de informação, pelo tipo de informação que requerem, se são informações de caráter geral ou especializado, pela idade, pelo tipo de unidade prestadora de serviço de informação, e por condicionante que determina a capacidade para acessar a informação, no caso, os aspectos econômicos, socais, culturais e nível de escolaridade.

\section{Resultados: apresentação e discussão}

Conhecer as características do público de uma biblioteca pode ajudar a gestão da mesma a compreender quem são seus usuários e, até mesmo, os usuários em potencial, e os não-usuários. As bibliotecas comunitárias, de modo geral, como sinaliza Machado (2008), tem como público a comunidade onde se insere, dessa forma, identificar os usuários que utilizam ou não os seus serviços, pode vir a auxiliar na tomada de decisão quanto à forma de promoção da biblioteca para a comunidade.

$\mathrm{Na}$ pesquisa, realizou-se a identificação da faixa etária dos usuários participantes do estudo, por meio da qual percebeu-se que, dentre estes, as crianças e jovens (entre cinco a quinze anos) estão entre os principais frequentadores das três bibliotecas, correspondendo a $63 \%$ na BCLB, $60 \%$ na BCMM e 26\% na BCDFL. As bibliotecas BCDFL e BCLB apresentam, ainda, boa representatividade na participação de adultos. No caso dos usuários que se encontram entre 26 e 35 anos, estes correspondem a $32 \%$ na BCDFL e $31 \%$ na BCLB. É relevante notar que a BCDFL possui também $26 \%$ de seus participantes com idade acima de 46 anos, valor equivalente à porcentagem do público infantil e juvenil.

Tabela 1 - Faixa etária dos participantes da pesquisa

\begin{tabular}{c|c|c|c|c|c}
\hline Caso/Biblioteca & $\begin{array}{c}\text { 07 a 15 } \\
\text { anos }\end{array}$ & $\begin{array}{c}\mathbf{1 6} \text { a 25 } \\
\text { anos }\end{array}$ & $\begin{array}{c}\mathbf{2 6} \text { a 35 } \\
\text { anos }\end{array}$ & $\begin{array}{c}\mathbf{3 6} \text { a 45 } \\
\text { anos }\end{array}$ & $\begin{array}{c}\mathbf{4 6} \text { anos ou } \\
\text { mais }\end{array}$ \\
\hline \hline 1-BCDFL & $26 \%$ & $11 \%$ & $32 \%$ & $5 \%$ & $26 \%$ \\
\hline 2-BCLB & $63 \%$ & $0 \%$ & $31 \%$ & $0 \%$ & $6 \%$ \\
\hline 3- BCMM & $60 \%$ & $13 \%$ & $7 \%$ & $13 \%$ & $7 \%$ \\
\hline
\end{tabular}

Fonte: Dados da pesquisa.

Se observarmos a distribuição dessas porcentagens entre as faixas etárias e as bibliotecas (apresentada na Tabela 1) é possível ponderar que a maior variedade de faixa etária encontrada na BCDFL possa se dá, também, pela variedade de serviços que a mesma oferece. Como foi dito, a BCDFL possui, além de serviços de empréstimo e mediação de leitura,

AMARAL, S. A. Mercadotecnia y estudios de usuarios para identificar y satisfacer las necesidades de información. In: SEMINARIO DE INVESTIGACIÓN SOBRE USUARIOS DE LA INFORMACIÓN, 9., 2014, México, Anais... México: Universidad de Chihuahua, 2014. 
ações como, atendimento médico gratuito duas vezes ao mês, aulas de aeróbica, oficinas de arte, aulas de violão, dentre outros. Essa variedade de serviços abrange o interesse de públicos de diversas idades. Assim, verifica-se que, dessa forma, esse equilíbrio entre as idades dos grupos de usuários da BCDFL seja o resultado da multiplicidade de opções que a mesma oferece. As bibliotecas BCLB e BCMM também oferecem diversos serviços às comunidades, porém, em menor variedade, focando, de modo geral, em atividades direcionadas ao público infantil, os quais correspondem a maior porcentagem de usuários, em relação aos demais participantes do estudo.

Os dados referentes a escolaridade dos participantes seguem com percentuais semelhantes aos dados indicativos de faixa etária. Entre as três bibliotecas, a maioria dos participantes é de crianças e jovens que, em alguns casos, está cursando o ensino fundamental, correspondendo estes a $65 \%$ na BCMM, 56\% na BCLB e $37 \%$ na BCDFL.

Entre os participantes jovens e adultos da BCDFL, 10\% cursam 0 ensino médio, $21 \%$ tem ensino médio completo, $16 \%$ ensino superior em andamento e $11 \%$ ensino superior completo. Na BCLB, $25 \%$ possuem ensino médio completo e $13 \%$ estão com curso superior em andamento. Já na BCMM, 14\% dos participantes estão cursando ensino médio, 14\% estão com ensino superior incompleto e $7 \%$ finalizaram o ensino superior. Na Tabela 2 é possível observar a junção desses dados.

Tabela 2 - Escolaridade dos participantes da pesquisa

\begin{tabular}{l|c|c|c|c|c|c}
\hline $\begin{array}{c}\text { Caso/ } \\
\text { Biblioteca }\end{array}$ & $\begin{array}{c}\text { Ensino } \\
\text { fundamental } \\
\text { incompleto }\end{array}$ & $\begin{array}{c}\text { Ensino } \\
\text { fundamental } \\
\text { completo }\end{array}$ & $\begin{array}{c}\text { Ensino Médio } \\
\text { incompleto }\end{array}$ & $\begin{array}{c}\text { Ensino } \\
\text { Médio } \\
\text { completo }\end{array}$ & $\begin{array}{c}\text { Ensino } \\
\text { Superior } \\
\text { incompleto }\end{array}$ & $\begin{array}{c}\text { Ensino } \\
\text { Superior } \\
\text { completo }\end{array}$ \\
\hline \hline 1- BCDFL & $37 \%$ & $5 \%$ & $10 \%$ & $21 \%$ & $16 \%$ & $11 \%$ \\
\hline $\mathbf{2 - B C L B}$ & $56 \%$ & $6 \%$ & $0 \%$ & $25 \%$ & $13 \%$ & $0 \%$ \\
\hline $\mathbf{3 - B C M M}$ & $65 \%$ & $0 \%$ & $14 \%$ & $0 \%$ & $14 \%$ & $7 \%$ \\
\hline
\end{tabular}

Fonte: Dados da pesquisa.

A concentração de maior porcentagem de usuários das três bibliotecas está no ensino fundamental, cuja maioria é constituída por crianças e jovens. Essa constatação pode ser justificada também pelos dados anteriores (tabela 1), acerca da influência dos tipos de serviços oferecidos pelas bibliotecas aos usuários que a utilizam. Como foi expresso por Machado (2008), o direcionamento de serviços e atividades desenvolvidos pelas bibliotecas comunitárias a públicos específicos da comunidade pode revelar que a biblioteca dá prioridade a determinados grupos por razões de necessidades inerentes à localidade. A exemplo de locais em que a falta de biblioteca escolar nas escolas da comunidade faz com que a biblioteca comunitária atue como espaço de reforço escolar, de atividades lúdicas e de leituras direcionadas ao público de infantil e jovem.

Com relação à frequência de utilização da biblioteca comunitária (Gráfico 1), identifica-se que parte considerável dos pesquisados costuma frequentar diariamente a biblioteca. Na BCLB, esses usuários correspondem a $88 \%$, na BCMM a 53\% e na BCDFL $47 \%$.

Gráfico 1 - Frequência de utilização da biblioteca comunitária 

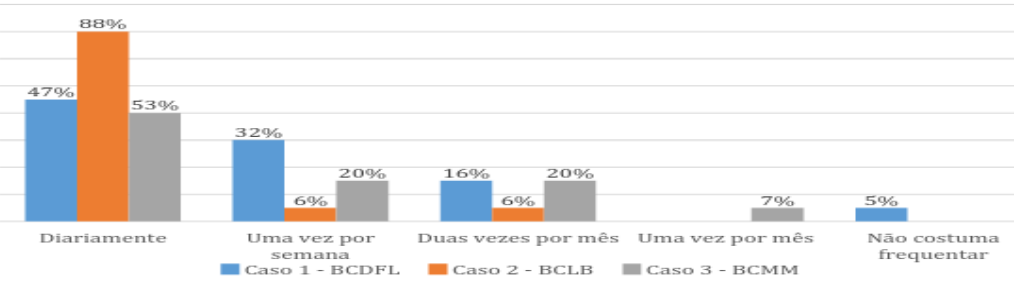

Fonte: Dados da pesquisa.

Por meio do gráfico 1 , é possível verificar que, em média, entre $15 \%$ e $20 \%$ dos participantes costumam frequentar a biblioteca uma vez por semana ou duas vezes por mês. Dentre os respondentes, apenas um informou não frequentar, estando assim caracterizado como não usuário da biblioteca.

Sobre o aspecto da frequência, vale refletir que a atuação e efetivação da biblioteca comunitária nas dinâmicas do cotidiano da comunidade é um ponto importante para que a mesma possa ser inscrita no contexto social do qual faz parte. E a oferta de ações culturais e serviços informacionais podem contribuir para essa efetivação.

Outro ponto contemplado no estudo foi a participação dos usuários nas atividades e nos serviços ofertados pelas bibliotecas. Nesse ponto, observou-se que as ações mais citadas foram as ligadas à leitura indicadas por mais de $60 \%$ dos usuários, seguidas da dança, com cerca de $50 \%$ de participação, e da música, também com cerca de $50 \%$ de participação. $O$ envolvimento em outras atividades, por exemplo cursos e palestras, foi indicado principalmente pelos participantes jovens e adultos.

No Gráfico 2, é possível observar como está distribuído o envolvimento dos usuários nas atividades e ações desenvolvidas.

Gráfico 2 - Participação nas atividades e nos serviços das bibliotecas

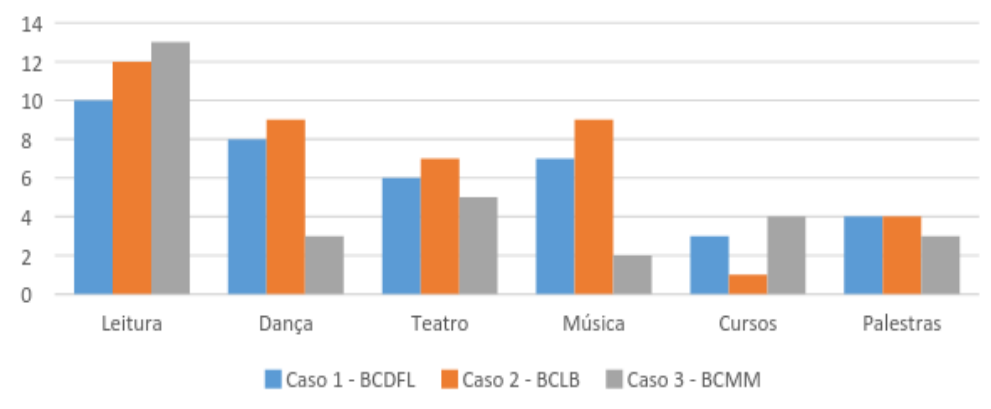

Fonte: Dados da pesquisa.

O interesse especial e o foco observados na atuação das bibliotecas, bem como na participação dos usuários em atividades relacionadas à leitura, vão ao encontro das características e dos conceitos acerca das bibliotecas comunitárias, como evidenciam os estudos de Machado (2008). Sobre isso, pondera-se que, a leitura é entendida como elemento inerente aos processos de inclusão social e informacional (FREIRE, 1984), dessa maneira, é possível compreender o porquê da forte presença de 
atividades envolvendo a leitura nesses espaços e o forte interesse gerado por ela.

Mas, e os usuários? Que visão eles têm da biblioteca? Que sentidos atribuem a ela? Descobrir qual a opinião dos usuários sobre a biblioteca fortalece a possibilidade de uma atuação dialógica, em que a comunidade possa ser efetivamente participativa. Vê-se no conceito de biblioteca comunitária, que a gestão participativa está dentre as principais características desses espaços (MACHADO, 2008). Para que isso ocorra, o diálogo entre comunidade e biblioteca é fundamental.

Nesse sentido, buscou-se, primeiramente, descobrir se os usuários consideram a biblioteca importante para a comunidade. Sobre isso, houve um entendimento unânime entre os participantes do estudo, de que as bibliotecas comunitárias são de grande valor. Os pesquisados da BCDFL atribuem essa importância, especialmente, à promoção da leitura e ao acesso ao livro, também aos projetos e ações desenvolvidos pela mesma e pela possibilidade de terem um espaço de desenvolvimento de atividades culturais e sociais, visto que a comunidade se encontra distante da zona urbana. Também, na BCLB e na BCMM, os usuários conferem à importância da biblioteca, de forma especial, à possibilidade de acesso ao livro e à leitura, e destacam a biblioteca como um espaço de convivência e de eventos de cunho cultural e educativo.

Os usuários indicaram a existência de benefícios à comunidade por meio da atuação da biblioteca. Na BCDFL, os participantes expressaram que, por meio da biblioteca, o acesso ao livro, à leitura e à informação foi ampliado. Além disso, disseram que a biblioteca oferece a opção de atividades que preenchem o tempo das crianças, jovens e adultos com momentos de leitura, cultura, educação e lazer.

Outro destaque se dá ao atendimento médico realizado na biblioteca, o que facilitou o acesso dos moradores da comunidade aos serviços de saúde. Na BCLB, seus usuários apontam que o gosto da leitura, especialmente das crianças e dos jovens melhorou, o que repercutiu na qualidade do aprendizado também na escola. Os pesquisados apontam, ainda, que os eventos e ações desenvolvidos pela biblioteca trouxeram a possibilidade de socialização e participação dos indivíduos da comunidade que não costumavam integrar-se. Segundo os usuários da BCMM, os benefícios advindos da atuação da biblioteca são principalmente o acesso ao livro e à leitura, mas, destacam ao mesmo tempo a opção de participar de atividades culturais, educacionais e sociais.

A leitura esteve presente de maneira significativa na fala de muitos participantes do estudo. É interessante perceber que a alusão feita à mesma nas respostas, está imbricada no imaginário de que a leitura é fator relevante no desenvolvimento humano e social e para a educação. Ao falarem do porquê da biblioteca ser importante para a comunidade e dos benefícios que ela trouxe, a leitura foi elemento central nas respostas, indicando que, para esses usuários, o acesso à leitura está ligado ao desenvolvimento local e à inclusão informacional. Esse imaginário da 
leitura como fator de desenvolvimento humano e social foi identificado também na Pesquisa Retratos da Leitura no Brasil (2012), a qual identificou que, em geral, os participantes da pesquisa relacionaram a leitura com a possibilidade de melhoria de vida.

Outro passo importante no diálogo entre biblioteca e comunidade é identificar como a biblioteca poderia vir a atuar para aprimorar seus serviços e sua atuação. Sobre esse aspecto, os usuários da BCDFL indicam que a biblioteca poderia ampliar o número de cursos e de horário de funcionamento também para o turno da noite e promover atividades de cunho esportivo. Os participantes da BCLB apontaram ser necessária a criação de atividades também com foco no público adulto, como cursos e oficinas. $\mathrm{E}$, em sentido semelhante, os usuários da BCMM também indicam a necessidade de realizar ações que envolvam o público adulto.

Percebe-se que as bibliotecas com foco principalmente no público infantil tiveram como principal ponto a melhorar, indicado pelos usuários, a investidura em ações direcionadas ao público adulto. Isso demonstra que esses usuários sentem a necessidade de que a biblioteca direcione sua atuação de forma a contemplar também outros grupos da comunidade.

Tendo por base essas informações e os critérios de classificação dos tipos de usuários estabelecidos por Amaral (2014, apud CUNHA; AMARAL; DANTAS, 2015), realizou-se uma adaptação onde congregamos a análise dos dados do estudo com os critérios estabelecidos pela autora. Na Tabela 3, essa relação pode ser visualizada da seguinte maneira:

Tabela 3 - Classificação dos tipos de usuários das bibliotecas comunitárias analisadas

\begin{tabular}{|c|c|c|c|}
\hline \multirow[t]{2}{*}{ CRITÉRIO } & \multicolumn{3}{|c|}{ CARACTERÍSTICAS DOS USUÁRIOS } \\
\hline & CASO 1 - BCDFL & CASO 2 - BCBL & CASO 3 - BCMM \\
\hline \multirow[b]{2}{*}{$\begin{array}{l}\text { Pelo uso que fazem da } \\
\text { unidade de informação }\end{array}$} & 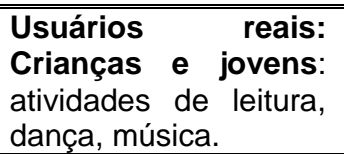 & $\begin{array}{l}\text { Usuários } \\
\text { Crianças e jeais: } \\
\text { atividades de leitura, } \\
\text { educação e música. }\end{array}$ & 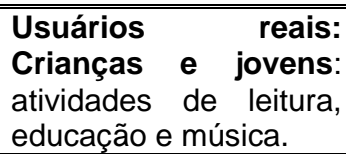 \\
\hline & $\begin{array}{l}\text { Usuários reais: } \\
\text { Adultos: atividades } \\
\text { como, cursos, } \\
\text { palestras, aulas de } \\
\text { aeróbica. }\end{array}$ & $\begin{array}{l}\text { Usuários reais } \mathbf{e} \\
\text { potenciais. } \\
\text { Adultos: atividades } \\
\text { como, cursos e eventos } \\
\text { culturais. }\end{array}$ & $\begin{array}{l}\text { Usuários reais } \mathbf{e} \\
\text { potenciais. } \\
\text { Adultos: atividades } \\
\text { como, cursos, oficinas } \\
\text { e esporte. }\end{array}$ \\
\hline $\begin{array}{l}\text { Pelo tipo de informação que } \\
\text { requerem }\end{array}$ & \multicolumn{3}{|c|}{ Informações gerais; Educação; Lazer. } \\
\hline Pela idade & \multicolumn{3}{|c|}{ Crianças, jovens e adultos. } \\
\hline $\begin{array}{c}\text { Pelo tipo de unidade } \\
\text { prestadora de serviço de } \\
\text { informação }\end{array}$ & \multicolumn{3}{|c|}{ Biblioteca comunitária. } \\
\hline \multirow{3}{*}{$\begin{array}{l}\text { Por condicionante que } \\
\text { determina a capacidade para } \\
\text { acessar a informação }\end{array}$} & \multicolumn{3}{|c|}{ Economia: agricultura, comércio e indústria } \\
\hline & \multicolumn{3}{|c|}{$\begin{array}{l}\text { Ocupação: estudantes, agricultores, donas de casa, aposentados. } \\
\text { Nível de formação: fundamental, médio e superior. }\end{array}$} \\
\hline & \multicolumn{3}{|c|}{$\begin{array}{c}\text { Geográfica: localização em zona rural, (a unidade de informação mais } \\
\text { próxima é a biblioteca comunitária) }\end{array}$} \\
\hline
\end{tabular}

Fonte: Baseado no modelo de Amaral (2014, apud CUNHA; AMARAL; DANTAS, 2015)

A opinião dos usuários acerca das bibliotecas se estabelece principalmente no entendimento dessas organizações como espaços de 
leitura e cultura para a comunidade, o que ressalta o fato de que a leitura ainda permanece como elemento central na visão das pessoas.

As bibliotecas comunitárias estudadas possuem diferentes tipos de usuários que, por sua vez, possuem interesses informacionais e culturais distintos. Identificar esses perfis torna-se bastante relevante para o sucesso da atuação da biblioteca comunitária como espaço de informação e cultura de uma comunidade.

\section{Considerações finais}

À luz dessas considerações, conclui-se que a biblioteca comunitária, amparada pelo status autônomo que possui, tem o potencial de atuar como um centro cultural e informacional, sendo reflexo da comunidade de que é parte. Diferentemente das bibliotecas ligadas a órgãos governamentais, público ou privado, as bibliotecas comunitárias possuem a autonomia de construir e seguir um projeto político-social criado de forma participativa e colaborativa. Porém, é importante considerar que, para alcançar seus objetivos de promoção da leitura e inclusão informacional, torna-se necessário o conhecimento da comunidade onde está localizada, o qual deve ser realizado de forma dialógica, levando em consideração o contexto social e as necessidades e interesses de seus indivíduos.

O diálogo entre biblioteca e comunidade deve ser contemplado na atuação da biblioteca comunitária. A gestão participativa nesses espaços poderá acontecer por meio dos estudos de usuários, visto que, ao perscrutar sobre os perfis e opiniões de seus usuários, a biblioteca abre espaço para que os mesmos participem e deem sua colaboração quanto aos serviços e atividades ofertadas, ao mesmo tempo que subsidiam novas formas de atuação.

Desse modo, compreende-se que, assim como demonstra a literatura contemplada neste estudo, os usuários dessas bibliotecas estudadas possuem múltiplos perfis e, por consequência, possuem diferentes demandas e comportamentos informacionais. Remetendo aos objetivos do estudo, conclui-se que foi possível observar que as bibliotecas analisadas possuem uma atuação voltada especialmente para ampliar e desenvolver os aspectos educacionais e culturais de suas comunidades. Por parte dos usuários das bibliotecas, constatou-se que há predominância principalmente de crianças e jovens, o que pode ser entendido como reflexo dos tipos de serviços oferecidos. A opinião dos usuários acerca da biblioteca, evoca o entendimento de que os mesmos atribuem a ela relevante grau de importância e, indicam, ainda, como resultado da atuação desses espaços, benefícios como: o acesso ao livro, à leitura, a atividades culturais, sociais, dentre outros.

Os estudos de usuários sob uma abordagem interacionista e social abre diversos caminhos para se pensar os usuários da informação em 
suas demandas e necessidades, pois, ao conferir caráter social à informação, abrem-se diversas perspectivas temáticas a se pesquisar. Ao pensar a relação biblioteca, comunidade e informação, tem-se uma gama de possibilidades para analisar os fluxos e usos da informação em contextos locais. Espera-se que, com as discussões e perspectivas aqui analisadas, novas pesquisas possam surgir, de forma a contemplar os estudos de usuários como ferramentas indispensáveis e que podem gerar interação e diálogo entre biblioteca e comunidade.

\section{Referências}

ARAÚJO, C. A. Á. Paradigma social nos estudos de usuários da informação: abordagem interacionista. Inf. \& Soc.: Estudos, João Pessoa, v. 22, n. 1, p. 145-159, jan./abr. 2012.

BAUMAN, Z. Comunidade: a busca por segurança no mundo atual. Rio de Janeiro: Jorge Zahar Ed., 2003.

CAPURRO, R. Epistemologia e Ciência da informação. In: ENCONTRO NACIONAL DE PESQUISA EMCIÊNCIA DA INFORMAÇÃO, 5., Belo Horizonte, 2003. Anais... Belo Horizonte: Escola de Ciência da informação da UFMG, 2003. p. 1-20.

CAVALCANTE, L. E. A mediação da informação sob a perspectiva do usuário em comunidades locais. In: CASARIN, H. de C. S. Estudos de usuários da informação. Brasília: Thesaurus, 2014. p. 255-271.

COSTA, M. F. O. Estudos de usuários a informação: ensino e aprendizagem no Brasil. Fortaleza: Edições UFC, 2016.

CUNHA, M. B; AMARAL, S. A; DANTAS, E. B. Manual de estudos de usuários da informação. São Paulo: Atlas, 2015.

DERVIN, B.; NILAN, M. Information needs and uses. In: WILLIAMS, M. Annual review of information science and technology. Chicago: Knowledge Industry Publications, 1986.

DIAS, M. M. K.; PIRES, D. Usos e usuários da informação. São Carlos: EdUFSCar, 2004.

FIGUEIREDO, N. M. de. Estudos de uso e usuários da informação. Brasília: IBICT, 1994.

FREIRE, P. A importância do ato de ler. São Paulo: Cortez, 1984.

GIL, A. C. Métodos e técnicas de pesquisa social. São Paulo: Atlas, 1999.

MACHADO, Elisa Campos. Bibliotecas comunitárias como prática social no Brasil. 2008. 184f. Tese (Doutorado em Cultura e Informação) - Escola de Comunicações e Artes, Universidade de São Paulo, São Paulo, 2008. Disponível em: <http://www.teses.usp.br/teses- 
/disponiveis/27/27151/tde-07012009-172507/pt-br.php>. Acesso em: 20 nov. 2016.

RÉMY, J. B. de O. Perfil de usuários, fontes de informação e constituição de acervos. In: CAVALCANTE, L. E.; ARARIPE, F. M. A. Biblioteca e Comunidade: entre vozes e saberes. Fortaleza: Expressão Gráfica e Editora, 2014. p. 71-88.

RETRATOS DA LEITURA no Brasil. Brasília: Instituto Pró-Livro, 2012.

SHANNON, C. E.; WEAVER, W. The mathematical theory of communication. Urbana: University of Illinois Press, 1949. 